\title{
Will coronary artery bypass grafting remain a standard of care for elderly patients with multivessel disease in the contemporary era?
}

\author{
M. Ono · Y. Onuma (iD · P. W. Serruys · J. J. Wykrzykowska
}

Published online: 31 July 2020

(c) The Author(s) 2020

Advanced age plays an important role in the pathogenesis of atherosclerosis. Therefore, older individuals with coronary artery disease tend to have more complex lesions (e.g. left main coronary artery disease or multivessel disease) than younger individuals. However, many randomised trials have excluded elderly patients based on their age or associated comorbidities, making it unclear what the optimal treatment strategy is for elderly patients with complex coronary artery disease. A higher prevalence of concomitant diseases and increased frailty may make clinicians hesitate to opt for a high-risk invasive strategy, such as cardiac surgery, and instead select a less invasive treatment, because of the potentially higher risk of periprocedural complications.

In this issue of the Netherlands Heart Journal, Gimbel et al. report that in their retrospective cohort of patients aged $\geq 75$ years with multivessel disease or left main coronary artery disease, coronary artery bypass grafting (CABG) was associated with significantly lower risks of mortality, acute coronary syndrome, repeat revascularisation and recurrent angina than percutaneous coronary intervention (PCI) [1]. In this trial, the completeness of revascularisation was not independently associated with the outcomes. However, the complete revascularisation rate was rel-

\section{Ono · J. J. Wykrzykowska}

Department of Cardiology, Heart Center, Amsterdam

University Medical Center, University of Amsterdam,

Amsterdam, The Netherlands

M. Ono $\cdot$ Y. Onuma $(\varangle) \cdot$ P. W. Serruys

Department of Cardiology, National University of Ireland

Galway, Galway, Ireland

yoshinobu.onuma@nuigalway.ie

\section{P. W. Serruys}

National Heart and Lung Institute, Imperial College London, London, UK atively low, especially in patients who underwent PCI (29.5\%). In the Synergy between PCI with Taxus and Cardiac Surgery (SYNTAX) randomised trial, this rate was $56.7 \%$ [2]. The main results are in line with those of past observational studies in which patients undergoing CABG showed lower mortality rates than those undergoing PCI or medical therapy [3, 4].

Nonetheless, potential confounders related to the selection of the revascularisation strategy cannot be excluded in an observational study. For example, in the SYNTAX randomised trial, which compared PCI and CABG in patients with three-vessel disease or left main coronary artery disease, patients who had only one of the two revascularisation options were excluded from the randomisation and were entered into nested registries of either PCI or CABG [2]. Compared with patients in the randomised PCI cohort, those in the PCI registry were on average older (71.2 vs 65.2 years) and had a higher mortality risk at 1 year $(7.3 \%$ vs $4.4 \%$ ), whereas those in the CABG registry showed a similar mean age (65.7 vs 65.0 years) and 1-year mortality risk (3.4\% vs $3.5 \%$ ) as the randomised CABG cohort. This discrepancy between PCI and CABG non-randomised cohorts indicate that more complex patients, such as elderly with multiple comorbidities, tend to undergo PCI rather than CABG, which can introduce biases in observational studies.

Unfortunately, no randomised trial comparing PCI and CABG specifically has so far been conducted in the older population with left main coronary artery disease or three-vessel disease. Age-specific subgroup analyses of several large randomised controlled trials may provide a less biased evaluation of the impact of the revascularisation strategy on clinical outcomes in those older patients (Fig. 1; [5-9]). However, those studies stratified 'elderly' patients by relatively younger age thresholds (63-67 years), and the numbers of elderly patients were limited. Therefore, 


\begin{tabular}{|c|c|c|c|c|c|c|c|c|}
\hline & \multirow{2}{*}{$\begin{array}{c}\text { Older } \\
\text { subgroup }\end{array}$} & \multirow{2}{*}{ Number } & \multirow{2}{*}{ Endpoint } & \multirow{2}{*}{ Timepoint } & \multicolumn{2}{|c|}{ Event rate $(\%)$} & \multirow{2}{*}{ HR $(95 \% \mathrm{Cl})$} & \multirow{2}{*}{$\begin{array}{c}\text { P for } \\
\text { interaction }\end{array}$} \\
\hline & & & & & CABG & $\mathrm{PCl}$ & & \\
\hline $\begin{array}{c}\text { LMCAD + MVD } \\
\text { Gimbel, et al. }\end{array}$ & $\geq 75$ years & 597 & Death & 5 years & 25.4 & 39.9 & $1.59(1.10-2.28)^{2}$ & $\therefore$ \\
\hline \multicolumn{9}{|l|}{ LMCAD } \\
\hline PRECOMBAT & $\geq 65$ years & 278 & MACCE $^{* 3}$ & 10 years & 31.4 & 36.3 & $1.30(0.87-1.95)$ & 0.99 \\
\hline EXCEL & $\geq 67$ years & 938 & Death, Ml, or stroke & 5 years & 21.8 & 27.2 & $1.39(1.02-1.89)$ & - \\
\hline NOBLE & $\geq 67$ years & 622 & $\mathrm{MACCE}^{* 4}$ & 5 years & 22 & 36 & $1.71(1.26-2.32)$ & 0.37 \\
\hline MVD + DM & & & & & & & & \\
\hline $\begin{array}{l}\text { FREEDOM } \\
\text { MVD }\end{array}$ & $>63.3$ years & 950 & Death & 8 years & 27.3 & 27.0 & - & 0.001 \\
\hline BEST & $\geq 65$ years & 481 & Death, MI, or TVR & 2 years & 11.9 & 17.9 & $1.51(0.95-2.42)$ & 0.90 \\
\hline LMCAD or 3VD & & & & & & & & \\
\hline SYNTAXES & $>70$ years & 575 & Death & 10 years & 39.6 & 41.4 & $1.06(0.82-1.37)$ & 0.30 \\
\hline
\end{tabular}

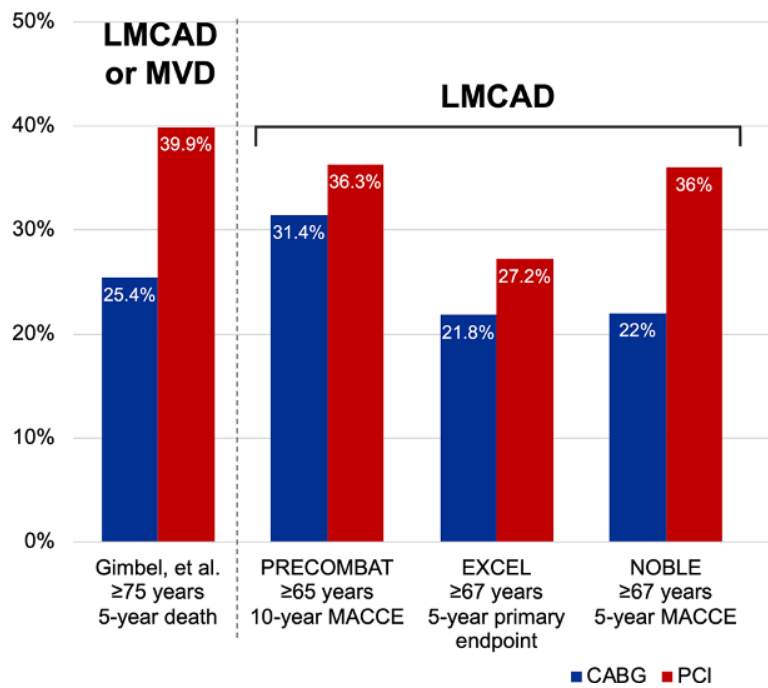

Fig. 1 Age-specific subgroups in large randomised trials comparing coronary artery bypass grafting versus percutaneous coronary intervention in patients with multivessel disease or left main coronary artery disease. $\left({ }^{*} P\right.$ value for interaction represents likelihood of interaction between agespecific subgroups and revascularisation strategy in each randomised trial. ${ }^{* 2}$ Adjusted hazard ratio by covariates. ${ }^{*}$ Defined as a composite of death, MI, stroke and ischaemia-driven TVR.

these results might be underpowered to determine the optimal treatment strategy for elderly patients with complex coronary artery disease. Recently, the results of the SYNTAX Extended Survival (SYNTAXES) trial, which was the extended 10-year follow-up of the SYNTAX trial, were reported. In the SYNTAXES trial, there was no significant difference in the risk of mortality at 10 years between CABG (39.6\%) and PCI (41.4\%) in the subgroup of patients aged $>70$ years with three-vessel disease or left main coronary artery disease [10].

Recently, the results of the International Study of Comparative Health Effectiveness with Medical and Invasive Approaches (ISCHEMIA) trial demonstrated that optimal medical therapy alone can be an alternative revascularisation strategy for the management of patients with moderate-to-severe myocardial ischaemia, although no age-specific result has been reported thus far [11]. The strategy of optimal medical therapy, however, does not work effectively without the patient's compliance and adherence. In the Trial of Invasive versus Medical therapy in the Elderly (TIME)
LMCAD

or 3VD

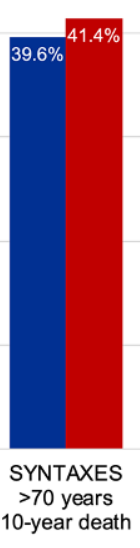

${ }^{*}$ Defined as a composite of death, non-procedural MI, repeat revascularisation and stroke. CABG coronary artery bypass grafting, $\mathrm{PCl}$ percutaneous coronary intervention, $H R$ hazard ratio, $\mathrm{Cl}$ confidence interval, $L M C A D$ left main coronary artery disease, $M V D$ multivessel disease, $D M$ diabetes mellitus, 3VD three-vessel disease, MACCE major adverse cardiac and cerebrovascular events, $M I$ myocardial infarction, TVR target vessel revascularisation)

study, optimal medical therapy alone was associated with a higher risk of major adverse cardiac events at 6 months than invasive revascularisation among patients with coronary artery disease $>75$ years [12]; the compliance and adherence to medical therapy were modest, even in the optimal medical therapy group. Moreover, $45 \%$ of patients in the optimal medical therapy group underwent revascularisation during the follow-up because of refractory symptoms.

The adherence to optimal medical therapy is also of paramount importance after PCI. However, an optimal regimen, especially regarding antiplatelet therapy, after PCI may be different for elderly and younger patients, since older patients tend to have a higher bleeding risk as well as a higher ischaemic risk than younger patients [13]. In the Clopidogrel Versus Ticagrelor or Prasugrel in Patients Aged 70 Years or Older With non-ST-elevation Acute Coronary Syndrome (POPular AGE) trial, clopidogrel was preferred over ticagrelor because of a significantly lower bleeding risk without an increase of net clinical events (composite 
of all-cause death, myocardial infarction, stroke, and bleeding) in patients aged $\geq 70$ years with a clinical presentation of non-ST-elevation acute coronary syndrome [14]. The discrepancy in the results between this elderly-specific study and past studies, such as the Platelet Inhibition and Patient Outcomes (PLATO) trial [15], suggests that the low bleeding risk antiplatelet strategy rather than a potent anti-ischaemic regimen would be favourable in elderly patients in the context of the contemporary PCI era. A recently proposed antiplatelet strategy, namely $\mathrm{P}_{2} \mathrm{Y}_{12}$ inhibitor monotherapy, has the potential to further improve the prognosis of elderly patients undergoing PCI [16].

As mentioned above, observational studies have an inherent limitation in comparing CABG and PCI. However, those trials suggest that CABG can achieve more favourable outcomes than PCI in a selected elderly population. Dedicated randomised trials comparing CABG versus PCI with a contemporary management strategy in elderly patients are warranted. Until the results of such trials are available, it is important that the Heart Team carefully evaluates the indication for CABG versus PCI versus optimal medical therapy on a case-by-case basis in the elderly population.

Conflict of interest P.W. Serruys reports personal fees from Biosensors, Micell Technologies, Sino Medical Sciences Technology, Philips/Volcano, Xeltis and HeartFlow, outside the submitted work. M. Ono, Y. Onuma and J.J. Wykrzykowska declare that they have no competing interests.

Open Access This article is licensed under a Creative Commons Attribution 4.0 International License, which permits use, sharing, adaptation, distribution and reproduction in any medium or format, as long as you give appropriate credit to the original author(s) and the source, provide a link to the Creative Commons licence, and indicate if changes were made. The images or other third party material in this article are included in the article's Creative Commons licence, unless indicated otherwise in a credit line to the material. If material is not included in the article's Creative Commons licence and your intended use is not permitted by statutory regulation or exceeds the permitted use, you will need to obtain permission directly from the copyright holder. To view a copy of this licence, visit http://creativecommons.org/licenses/by/4.0/.

\section{References}

1. Gimbel ME, Willemsen LM, Daggelders MC, Kelder JC, Oirbans T, Beukema KF, et al. Long-term follow-up after bypass surgery or coronary stenting in elderly with multivessel disease. Neth Heart J. 2020; https://doi.org/10.1007/s12471020-01415-z.

2. Serruys PW, Morice MC, Kappetein AP, Colombo A, Holmes DR, Mack MJ, et al. Percutaneous coronary intervention versus coronary-artery bypass grafting for severe coronary artery disease. NEnglJ Med. 2009;360(10):961-72.
3. Graham MM, Norris CM, Galbraith PD, Knudtson ML, Ghali WA. Quality of life after coronary revascularization in the elderly. Eur Heart J. 2006;27(14):1690-8.

4. Nicolini F, Contini GA, Fortuna D, Pacini D, Gabbieri D, VignaliL, etal. Coronaryarterysurgeryversus percutaneous coronary intervention in octogenarians: long-term results. Ann Thorac Surg. 2015;99(2):567-74.

5. Stone GW, Kappetein AP, Sabik JF, Pocock SJ, Morice MC, Puskas J, et al. Five-year outcomes after PCI or CABG for left main coronary disease. N Engl J Med. 2019;381(19):1820-30.

6. Holm NR, Makikallio T, Lindsay MM, Spence MS, Erglis A, Menown IBA, et al. Percutaneous coronary angioplasty versus coronary artery bypass grafting in the treatment of unprotected left main stenosis: updated 5-year outcomes from the randomised, non-inferiority NOBLE trial. Lancet. 2020;395(10219):191-9.

7. Park DW, Ahn JM, Park H, Yun SC, Kang DY, Lee PH, et al. Ten-year outcomes after drug-eluting stents versus coronary artery bypass grafting for left main coronary disease: extended follow-up of the PRECOMBAT trial. Circulation. 2020; https://doi.org/10.1161/CIRCULATIONAHA. 120.046039 .

8. Farkouh ME, Domanski M, Dangas GD, Godoy LC, MackMJ, Siami FS, et al. Long-term survival following multivessel revascularization in patients with diabetes: the FREEDOM follow-on study. J Am Coll Cardiol. 2019;73(6):629-38.

9. Park SJ, Ahn JM, Kim YH, Park DW, Yun SC, Lee JY, et al. Trial of everolimus-eluting stents or bypass surgery for coronary disease. NEnglJ Med. 2015;372(13):1204-12.

10. Thuijs D, Kappetein AP, Serruys PW, Mohr FW, Morice MC, Mack MJ, et al. Percutaneous coronary intervention versus coronary artery bypass grafting in patients with threevessel or left main coronary artery disease: 10-year followup of the multicentre randomised controlled SYNTAX trial. Lancet. 2019;394(10206):1325-34.

11. Maron DJ, Hochman JS, Reynolds HR, Bangalore S, O'Brien SM, Boden WE, et al. Initial invasive or conservative strategy for stable coronary disease. $\mathrm{N}$ Engl J Med. 2020;382(15):1395-407.

12. TIME Investigators. Trial of invasive versus medical therapy in elderly patients with chronic symptomatic coronary-artery disease (TIME): a randomised trial. Lancet. 2001;358(9286):951-7.

13. Matteau A, Yeh RW, Camenzind E, Steg PG, Wijns W, Mills J, et al. Balancing long-term risks of ischemic and bleeding complications after percutaneous coronary intervention with drug-eluting stents. Am J Cardiol. 2015;116(5):686-93.

14. Gimbel M, Qaderdan K, Willemsen L, Hermanides R, Bergmeijer T, de Vrey E, et al. Clopidogrel versus ticagrelor or prasugrel in patients aged 70 years or older with nonST-elevation acute coronary syndrome (POPular AGE): the randomised, open-label, non-inferiority trial. Lancet. 2020;395(10233):1374-81.

15. Wallentin L, Becker RC, Budaj A, Cannon CP, Emanuelsson $\mathrm{H}$, Held $\mathrm{C}$, et al. Ticagrelor versus clopidogrel in patients with acute coronary syndromes. N Engl J Med. 2009;361(11):1045-57.

16. Tomaniak M, Chichareon P, Modolo R, Takahashi K, Chang CC, Kogame N, et al. Ticagrelor monotherapy beyond one month after PCI in ACS or stable CAD in elderly patients: a pre-specified analysis of the GLOBAL LEADERS trial. EuroIntervention. 2020;15(18):e1605-e14. 